\title{
Fab! Or Drab? Increasing the Effectiveness of Teaching and Learning in Summer Classes
}

\author{
Mariya Y. Omelicheva \\ Department of Political Science \\ University of Kansas \\ 1541 Lilac Lane \\ 412 Blake Hall \\ Lawrence, KS. USA, 66044 \\ omeliche@ku.edu
}

MARIYA Y. OMELICHEVA is an Assistant Professor of Political Science at the University of Kansas. She holds PhD (2007) in Political Science from Purdue University and JD in International Law (2000) from Moscow National Law Academy. Her research and teaching interests include international and Eurasian security, counterterrorism and human rights, and Russia's foreign policy. She has also published on the issues of students' assessment and application of various research techniques to the analysis of learning outcomes. 
Fab! Or Drab? Increasing the Effectiveness of Teaching and Learning in Summer Classes

This article reviews the pitfalls and benefits of teaching and learning in summer school and identifies the lack of student interest as the key factor affecting the effectiveness of learning in the summer. The primary goal of this research is to investigate the impact of active learning strategies on generating student interest and improving their learning in summer school. This article presents results of the study embedded into the classroom curriculum of a summer course. The study consisted of a series of active-learning interventions, surveys of students, and observations of their academic performance. The scores of students enrolled in the summer class were compared to academic results of those students who took a similar course during the regular terms. The evidence examined in the study demonstrates that active learning strategies can increase students' situational interest in the summer school setting and improve the quality of their learning.

Key words: summer teaching, active learning strategies

It is usually around the closing of the fall semester or at the beginning of the spring term that colleges and universities send out calls for summer course offerings and summer teaching. Most of the faculty in American universities is offered a choice of whether or not to teach summer school. Many instructors reluctantly sacrifice their summer vacations for extra financial reward. But even those professors who vehemently oppose the idea of giving up time with the family and forgoing opportunities for research are, compelled, now and then, to entertain a possibility of teaching in the summer. 
Since the late 1950s, American universities have been offering summer school opportunities to students. The need for a year-long education has been dictated by changes in the American families, extension of high school education, reforms of the university curriculum, and growing demands for the higher education that is competitive internationally. The universities' summer modules have served manifold purposes. Traditionally, they have been designed to assist students with weak academic performance to catch up on their course work. Over time, summer sessions have become viewed as an extension of the academic year program providing students with additional opportunities in designing a more flexible course schedule, accelerating progress toward their degree, and enriching their educational experiences outside their majors (Cooper et al. 2000, 5; Crowe et al. 2005, 7). In those universities that offer a flexible teaching schedule, summer school has been used for lightening educators' teaching load during the academic year and freeing their time for doing research.

There are, however, important challenges to teaching and taking courses in summer school. Since summer sessions are much shorter than regular semesters, both instructors and students are required to teach and learn more in a short period of time and, therefore, need to cope with the intensity of summer modules. For many students, summers are the time for earning income to pay for the school and living expenses during the academic year. These full- and parttime employed students tend to be particularly inattentive and unenthused in summer school. Educators, too, bear the risk of a burnout resulting from the year-long instruction and need to find solutions to teaching fatigue. Furthermore, teaching in the summer can be particularly challenging for those members of the faculty who need publications for their promotion and tenure. Summer teaching has long been perceived as an unfortunate tradeoff for months of productive research. ${ }^{1}$ 
What are the ways of maximizing benefits and minimizing drawback of teaching and learning in summer school? The review of the available information on summer teaching articles, instructors' commentaries, and teachers' blogs - revealed considerable interest in improving students' and instructors' experiences with summer courses. This interest, however, has been unmatched by the availability of systematic analyses of factors affecting teaching and learning in summer school. ${ }^{2}$ Although, there is a general consensus in the literature that instructors need to re-tool their teaching repertoire and adapt their curriculum to a different pace and structure of summer courses, there has been little discussion addressing effective teaching strategies in summer school. The purpose of this paper, therefore, is to examine the factors that have an impact on the success of summer modules. It is argued that many common problems associated with summer school affect student motivation for learning, while the reduced students' interest influences their academic achievements and performance during summer school. This article discusses the author's experiences of teaching a summer module and presents results of the study embedded into the classroom curriculum, which explored the impact of active learning strategies on increasing student interest and improving their learning in summer courses.

The article begins with a brief discussion of the importance of active learning strategies for generating students' interest and enhancing their academic performance in summer modules. Section two presents a research design of the study followed by the analysis of findings in section three. The last section offers tips and words of advice for more effective teaching and learning in the summer. Many of these recommendations are applicable for teaching during the regular school terms, but they are particularly useful for those educators considering or doing summer teaching. 


\section{Active Learning Strategies for Learning in Summer Courses}

Beginning with the seminal work of a German-American psychologist, Kurt Lewin (1951), who made a profound impact not only on social psychology, but also pedagogy, learning has been viewed as encompassing three interrelated spheres of knowledge, attitudes, and practice. For deep learning to take place, a learner's cognitive, affective, and behavioral systems, i.e., her ideas, feelings, and actions, must be engaged. The most successful teaching strategies are those that can simultaneously develop these three sides of human personality - intellectual, affective, and practical. Effective learning entails acquiring new knowledge, practical and thinking skills, and also engaging students' emotional side consisting of their interests and attitudes toward the course subject. The lack of interest in acquiring and applying new knowledge can inhibit students' ability to obtain an in-depth understanding of the course material as well as to develop more complex skills of well-reasoned thinking. Without some concern about the topics of the course curriculum, students will have no desire to seek and use new knowledge and skills.

Although, disinterested students are one of the stickiest problems during any school term, this problem is particularly relevant for summer modules. The heat and swelter of summer months and three-hour long meetings in classrooms, which can often get overheated, are not a pleasant experience conducive to capturing and maintaining student interest. The intense nature of summer programs’ curriculum, work overload, and other drawbacks of summer courses wreak havoc on students' interest and motivation to take part in summer school. Students' interest, on the other hand, is the most important motivational construct that influences their academic performance and achievement in learning (Hidi and Harackiewicz 2000; Subramaniam 2009). The pivotal issue of summer courses, therefore, revolves around the question about the ways of inducing and sustaining students’ interest in learning during summer months. 
Students arrive at college with already established interests, which scope and intensity varies from student to student. Educators have very little ability to change and exercise control over those individual interests. What teachers do have control over and can influence is the learners' situational interest. The latter is linked to the environment in which students acquire and practice their new skills and knowledge. The positive aspects of summer school mentioned in the literature on summer teaching, such as the smaller class size allowing for better teacher/student contact and stronger classroom rapport, all relate to student learning environment. The latter can also be enhanced through various contextual factors, particularly, modifications in teaching strategies, which affect the learning experiences of students. The learning environment that offers students a meaningful content and provides them with opportunities to talk, interact, read, write, and reflect on the course material is critical to the enhancement of students' situational interest. Such an educational environment can be created by implementing active learning strategies for teaching and learning (Chen et al. 2001; Hidi and Harackiewicz 2000; Issac et al. 1999; Meyers and Jones 1993; Subramaniam 2009). Those instructors who chose to share their summer teaching experiences in articles or teachers’ blog name active learning strategies as an essential ingredient to an effective teaching and learning in summer school.

The expectation of this study, therefore, is that by incorporating more active learning strategies into the summer teaching, compared to teaching during the regular terms, an educator will be able to generate greater student interest and improve their learning in summer modules. Active learning, in simple terms, refers to a wide variety of models of instruction that have one thing in common: they make students do something instead of being passive recipients of information transmitted from their instructor. Active learning approaches focus on developing 
higher-order thinking skills and practical competencies through engagement in various educational activities encompassing discovery, processing and application of information. Active learning models of instruction place much greater emphasis on the affective side of learning, including students' interests, attitudes, and values (Bonwell and Eison 1991, 2). Research and other forms of evidence collected in the classroom overwhelmingly support the claim that students learn best when they engage in active learning, a model of instruction that engages cognitive, practice, and affective sides of human personality (Meyers and Jones 1993; Mohamed 2008; Williamson and Gregory 2010).

\section{Research Design}

To test the hypothesis about the impact of active learning strategies on student learning in summer courses, I designed a study embedded into the classroom curriculum of one summer class. The study consisted of a series of active-learning interventions, described in greater detail below, as well as students' surveys and observations of their academic performance. Results of the analysis of students' performance in the summer class were compared to students' scores obtained in similar courses taught during the regular terms.

\section{Description of the Courses}

The study was carried out in a course titled, Introduction to International Politics (Intro to IR) taught in the summer of 2010. Intro to IR is an introductory-level course that is regularly offered by the department of political science at a large-size research university located in the Midwest. All political science majors are required to take the course, but it can also be used for fulfilling general education requirements by students from other majors. In a regular semester, the course enrollment may top 250 students, but in recent years it has decreased to between 150 and 200 students. In the summer, 20 to 45 students enroll in the course (see Table 1). 


\section{TABLE 1 ABOUT HERE}

The curriculum of this course is designed to advance students' understanding of international politics and assist them in gaining critical knowledge about the major participants, issues, and processes in contemporary international relations. The list of the topics for the course encompasses themes and subjects that students should know to excel in their future studies in the

fields of international relations. As any introductory course, Intro to IR offers the wealth of material and familiarizes students with various theoretical frameworks.

Besides Intro to IR taught in the summer of 2010, I used data from two Intro to IR courses that I offered during the regular semesters in Fall 2009 and 2010. All three classes (Fall 2009, Summer 2010, and Fall 2010) had the same textbook and other reading assignments, and similar written assignments. The structure of the midterm and final exams was also exactly the same and both exams were offered online. The same examination questions were used in all classes. The pivotal difference between the regular semester classes and the summer course was in the amount of active learning tasks that were utilized in the summer module. Summer 2010 Intro to IR course was the test course where I introduced active learning interventions, whereas Fall 2009 and Fall 2010 Intro to IR courses became comparison courses used as reference points for assessing the quality of student learning in the summer module.

\section{Description of the Sources of Data and Active Learning "Interventions"}

In-class observation, student written commentaries and evaluations, exam scores, final grades, as well as entry and exit surveys of students were used as the sources of data for this study. Two survey questionnaires were designed to tap into different aspects of students' situational interest and their perceptions about the quality of learning in the summer module. The first questionnaire was filled out on the first day of the summer class. The entry survey also inquired about students’ 
expectations of the summer module and any concerns they might have had about summer school in addition to general questions about students' educational level, major, and experiences with summer school. The second survey was administered during the last class meeting. It invited students' responses to questions about whether or not the class fulfilled their expectations and asked to compare their experience in the summer class to other regular and summer courses. In addition, the second survey contained open-ended questions to elicit students' feedback on what they liked the most about the course, and what they would have changed about the summer module. Students’ responses to both surveys were completely anonymous.

For the active learning “interventions,” I devised a set of concrete active learning strategies and incorporated those into each class meeting during the four-week long summer course. To design interventions capable of triggering student interested, I created the 3R\&E rule and applied it to all readings, assignments, and exercises used in the summer session. The 3R stands for Reason, Relevancy and Recency of the material, while E is for Engagement. It has been demonstrated that those methods of instruction that make the class content more meaningful to students and connect it to their experience and prior knowledge can enhance their situational interest (Chen et al. 2001; Subramaniam 2009).

The application of the 3R\&E rule led to the following modifications to the classroom curriculum in the summer module. The summer term began with a series of ice-breakers, during which students could introduce themselves and share their expectations about the course. Information about students' backgrounds and personal interests collected at the beginning of the term was used later in the course for making necessary adjustments to lectures, exercises, and examples in order to make them more relevant and current for students and, therefore, more interesting. I also articulated my own expectations about the course, its goals, and students' 
performance, and held a discussion about how the course objectives related to those of the students and why it was worthwhile for them to be in the course. All academic assignments and tasks were linked back to the course objectives and students’ personal goals through conversations about the importance of reading a particular text or carrying out a specific academic task.

To include more active learning tasks, lecture presentations were kept very short - no more than 10-15 minutes at a time. Some changes in the method of instruction were introduced every 15-20 minutes. I mixed up discussions, group work, individual exercises, and educational games. For instance, students would work individually or in small groups on simple, current, and relevant case studies or problems for 10-20 minutes, and this work would be followed by the presentation of theoretical and conceptual frameworks that would be later applied for examining and finding solutions to the same or different problems. I also devised various discussion and testing techniques that were incorporated into lecture presentations. For instance, each student would receive a set of numbered or colored index cards with each number/color representing a position or attitude toward an issue. During the lecture, I would pose a question or read a scenario followed up by multiple responses or solutions to the problem. Students, then, would raise a card that they thought corresponded to the correct answer. Alternatively, I would bring up a controversy and solicit students' opinions. The colored cards, then, would be used for expressing students' attitudes toward the issue. The instructor would call on a student who chose the correct/incorrect answer or a particular attitude and have him or her explain it. This would be followed by a discussion with other students espousing alternative or competing viewpoints.

What makes these kinds of tasks "active" and different from the "show of hands" is that they compel all students to take a stance and choose a response. The cards take away an 
opportunity to hide behind other peers' hands and have a few super-achievers carry all class discussions. Students are aware that they may be called on to explain their choice, indicated by the card, and this forces them to engage with the course material. For the instructor, colored cards provide immediate feedback about what students are learning and how the opinions and attitudes are distributed in the class.

Besides small active learning tasks, I devised several active learning assignments that replaced my lectures in the summer module. One of those assignments was the Press Conference. I created it with the purpose of enlivening the discussion and analysis of various important issues of international politics, such as nuclear non-proliferation, poverty, climate, and others that students, in my classes, have found boring when I solo-lectured about them. This assignment was to be carried out in small groups of 4-6 students with each team taking on responsibility for collecting additional information and learning a particular topic in more depth. On the day when the topic was scheduled for discussion, the team of those responsible for the topic would hold a classroom press conference. During this event, the group's members would play the role of experts and the rest of the class - the role of journalists. The journalists would be required to do a textbook reading and prepare 3-5 questions that they could address to any expert on the team. The expert would answer the question him/herself or consult with the team. Other experts on the team would make additional comments following the original answer. To ensure active engagement of "journalists" into the discussion, the Press Conference assignment was augmented with the press release task. All those students who were not the members of the team of experts would be given time during the class to write-up summaries of press conference in the form of press release. 
Two variations of the Press Conference assignment that I used in the summer course were Team Quiz and Questions Game. For the former, the class was divided into teams each responsible for preparing analytical or factual questions for a portion of the reading assignment. In class, an emcee from Team 1 would address one of the questions to a selected student from Team 2. If the student gave a correct answer, his/her team would get 2 points, if the student consulted the team - 1 point, and if the answer was incorrect - 0 points. In the Questions Game, each student was asked to prepare 5-10 question cards with one side of each question card containing a question in any format, and another side - a correct answer or a definition of the term. During the class meeting, the class would be divided into small groups. Each group would mix up individual members' question cards and exchange the pile of cards with another group. Individual instructors can modify the final stages of the game and use various strategies for evaluating students’ responses and scoring.

A common feature of all these active learning assignments is that they shift responsibility for learning on students with the instructor playing the role of a facilitator of learning. In these assignments, the students are actively involved in reading, crafting questions, seeking solutions, and testing the knowledge of their peers. Academic performance in the presence of other students has a positive impact on the development of their situational interest (Isaac at al. 1999). Furthermore, students are typically more productive and involved when they work with other students on learning tasks (Dyson 2002).

\section{Assessing the Impact of Active Learning Strategies in a Summer Course}

A total of 24 students were enrolled in the summer course used for the purpose of the study. Compared to the Intro to IR courses taught in the regular semesters, summer class had more seniors and juniors (38 and 46 percent respectively) than freshmen and sophomore students (6 
and 10 percent accordingly). The majority of those enrolled (almost 71 percent) were from the college of liberal arts. One quarter of the students listed political science as their major or comajor. Only two students said they had taken the course before and were re-taking it for the second time. Almost three-quarters of the students enrolled in the summer course were taking other classes during the same summer term, and 60 percent said they had taken summer courses before. More than a half of the students worked part or full-time during the summer. The range of work hours reported by students was between 7 and 40 hours a week.

In terms of the primary reason for summer school enrollment, almost 70 percent of students said they wanted to accelerate the advancement toward their college degree. Another reason listed was to get general education courses out of the way and graduate on time. The same two reasons were mentioned for enrolling in other summer courses. Only two students specifically identified strong interest in international relations as one of the reasons for enrolling in the Intro to IR class. Almost every student - 88 percent of the class - mentioned that getting an "A" was his or her expectation of the summer module. Two students noted that they expected to gain a better understanding of politics beyond nation-states and how the rest of the world evaluated the US foreign policy. Only one student specified that by enrolling into the course she felt she was fulfilling her responsibility as a student and a citizen in obtaining an education in the nature of political processes in the field of international relations.

When asked whether or not they wanted to be in the summer class, about one-quarter of the students replied they wanted to be in the class very much, and 44 percent chose "somewhat." Almost 15 percent of students said they did not really want to take the summer course or chose "not at all" in response to the same question. Four students who said they wanted to be in the summer class explained it by linking their preference to their interest in the content of the course 
and intention to graduate on time. All students who said they did not want to be in the class also reported the lack of interest in the content of the summer module. The second reason indicated by the students who did not want to be in the class was the fact that it was offered during the summer.

The students demonstrated some awareness of both benefits and drawbacks of studying in the summer. Among the major advantages, they listed the opportunity to finish classes quicker (35\%), to get ahead on one’s academic plan of study (38\%), and free time during the regular terms (9\%). They also liked that they could stay more focused or pay more attention to studying during the summer months (12\%). They enjoyed the atmosphere of the small classes, attention received from their instructors, and closer interaction with other students in the class (7\%). Among the major drawbacks, almost every student mentioned the intensity of summer sessions (83\%). The long duration of summer classes, the fact that they were offered during the summer months, and that students had to forgo money-making opportunities and vacation time - all appeared on the list of disadvantages of studying in the summer (15-25\%). These students' expectations and views on the benefits and pitfalls of studying in the summer were consistent with those expressed in the literature on summer teaching and instructors’ blogs.

According to students' comments, they all liked the summer course and commended it for providing them with learning opportunities in the summer module. Below are some quotes from the students’ exit survey. One learner stated that “the class was a worthwhile experience” while another admitted that he "enjoyed the class a lot more than [he] thought [he] would." Another student commented that the summer course triggered his interest in learning more about international relations making him ponder whether or not to change his major to political science. One of the recurrent themes of the written feedback received from the students was that the 
course surpassed their expectations. This was further confirmed in the students' responses to the close-ended questions. When asked whether or not the summer class met their expectations, 41 percent of students said that the class exceeded their expectations, while 45.5 percent reported that the course met their expectations.

The students were also asked to compare the summer class to other courses that they took during the regular and summer semesters along the dimensions of knowledge acquisition, development of critical thinking skills, the level of engagement, and others. According to the survey's results, 13.6 and 50 percent of students thought that they gained much higher or higher knowledge in the summer class compared to other courses. Only 22.7 percent said the amount of knowledge they received in the summer course was the same. With regard to analytical skills, 22.7 and 54.5 percent of students said that their critical thinking significantly improved or simply improved, while 9.1 percent thought they remained unchanged. Almost 90 percent of students agreed or strongly agreed that the format of the class, which offered a good balance of lectures, exercises, discussions, and group work, was a useful approach to teaching the course material. Only 4.5 percent of students strongly agreed with the statement that the summer course was too intense and 22.7 percent agreed somewhat with this statement.

The open-ended feedback provided by the students can shed some light on those aspects of the summer course that contributed to their interest and learning the most. Almost every student commented on how much he or she liked discussions and Q\&A exchanges in and outside groups, particularly, the Press Conference assignment. According to some, the class offered a “refreshing level of interaction”, while others opined that by making everyone involved and relating the information to students' experience and prior knowledge the instructor was able to stimulate their interest in the topics of the class. Many students mentioned that they learned the 
most through in-class discussions. One student shared, "while some opinions and viewpoints were, at times, unsettlingly conservative to the point of ignorance, I feel like I learned a lot in those discussions and they were very engaging and fun.” These and other comments indicate that active learning strategies that were introduced in the summer course were effective in enhancing student interest. Students enjoyed the level of participation and involvement in the class, and, as a result, their self-perception of learning was very high as well. A frequent comment that I found in the surveys was that students "learned a lot" in the summer class.

To validate students’ self-reports about learning in the summer module, I compared students' performance in the summer class to students' scores from the Intro to IR courses taught in Fall 2009 and Fall 2010. As can be seen in Table 2, 56.5 percent of students in the summer class received an "A”, compared to 40.3 and 24.2 percent of students with excellent performance in the Fall 2009 and Fall 2010 semesters. The mean final percentage for the summer class was 86.9 (on a 100-percent scale), which was also greater than the mean percentage point for the Fall 2009 class ( $M=85.79)$ and, especially, for the Fall 2010 class ( $M=81)$. In the latter case, the difference was also statistically significant based on the results of the Independent-Samples T test $(t=2.16, p=0.03)$.

To assuage concerns about the possibility that the closer interactions of the instructor with her students and greater classroom rapport affected her perception of the student learning in the summer module, scores on the midterm and final exams were used as an additional measure of student performance. To reiterate, midterm and final exams in the summer class and regular semester courses were structurally and content-wise the same. They were offered online and consisted of identical multiple-choice and short answer questions. Students in the summer course also did better than the students in the regular semester on both midterm and final exams. The 
mean midterm score for the summer course was 8.8 (on a 10-percent scale), compared to 7.9 and 8.2 in the Fall 2009 and Fall 2010 semesters. The differences between the means of scores on the midterm are statistically significant for a comparison of the summer term to Fall 2009 term $(t=1.4 ; p=0.04)$ and to Fall 2010 term $(t=2.4 ; p=0.017)$. As for the final exam, the mean score for the summer class students was 8.3 (on a 10-percent scale), whereas for those enrolled in the regular 2009 and 2010 semesters, it was 8.1 and 7.5 correspondingly. The difference was statistically significant for a comparison with the Fall 2010 class $(t=2.6 ; p=0.01$. This comparative evidence suggests that by adding more interactive and participatory activities and cutting down on lecturing and, in some instances, on the content of the course, I did not sacrifice the quality of student learning. If anything, students learned better in the summer class.

\section{TABLE 2 ABOUT HERE}

All of the accumulated evidence demonstrates that students liked the course and with the increased situational interest the quality of their learning also improved. The summer class was successful largely due to the integration of the material that was appealing to students and introducing high level of students’ engagement “while maintaining sufficiently high expectations”. The latter quote from a written comment by another student from the summer module is very important because there is a popular belief that summer classes are sympathy sessions where grades and credits are doled out without the due consideration of the academic merit. In their course evaluations, more than 60 percent of students from the summer module strongly agreed that the summer class expectations were appropriately challenging, and 20 percent of students agreed with this statement. Almost 80 percent of students from that class strongly agreed that those challenging expectations were well defined and fair. In the regular 2009 term, just over 50 percent of students strongly agreed that the course was appropriately 
challenging, whereas in the regular 2010 term less that 40 percent of the students strongly agreed with this statement. Of those who filled out course evaluations in the Fall 2009 term, about 50 percent of students strongly agreed that the expectations were fair and well defined. In Fall 2010, just over 40 percent of students strongly agreed with this statement.

\section{Concluding Remarks and Recommendations on Summer Teaching}

What follows are some words of advice from the veteran summer teachers that I found extremely helpful in thinking about, devising, and teaching my summer class. Many of these recommendations can be found in the scholarship on summer teaching and are also supported by my personal experiences with teaching the summer class.

Since learning environment largely determines the quality of student learning, the first recommendation concerns the ways of structuring learning environment in summer school. Just like the architects plan, design, and oversee the construction of buildings, instructional designers create and administer effective learning environments. Instructional strategies can be thought of as building blocks of an educational style, which effectiveness varies depending on how closely it matches human cognitive processes, engages students' emotions and interest, and supports the broad variability of learning styles. This study demonstrated that the learning environment revolving around engaging and participatory assignments providing students with opportunities to meaningfully talk, deliberate, and interact with their instructor and peers can significantly increase their situational interest in summer courses. Situational interest, in turn, is one of the most important determinants of the quality of student learning in summer school.

Classroom rapport is another component of an effective learning environment. The size of summer classes is conducive for in-class interactions and small group work, which can promote student learning and facilitate their rapport. An educator can take advantage of the 
opportunities offered by teaching a small group of students and get to know their backgrounds, learning needs, concerns, and expectations of the course. This information can be used for the benefit of teaching and learning. It can assist educators in making course assignments more relevant to students and adjusting their lesson plans in such a way that the new material complements what students already know.

Instructors' attitudes toward summer teaching are also very important. Before taking on a commitment for teaching a summer class, an educator should reflect, objectively, on whether there is the zest and energy for teaching a summer module. After the school year is over, everyone feels exhausted, tired of students and one’s own discipline, and simply intellectually spent. Summers provide the much-needed respite for reinvigorating interest and re-building the stamina for teaching during regular semesters. If, at the end of the school year, the level of energy and excitement is extremely low, it may be better to pass on the opportunity of teaching a summer course. Once the decision to teach a summer course is made, it becomes an instructor's responsibility to deliver good teaching. Setting a clear intent to have a positive experience with summer teaching can make things flow much easier in summer school, and the summer session will go by much faster.

Still, stress and tiredness are inevitable when one has to teach every day, especially if the instructor is a novice in the teaching profession. To minimize the hassle and strain while teaching a summer module, it is advisable to take extra time to re-tool teaching strategies and lesson plans in advance. In my case, some extra work that I put into the development of assignments for the course prior to the summer term well paid off. It reduced the amount of pressure during the summer months and left me with sufficient time for doing research and other activities. In addition to preparing for summer classes before the beginning of the summer module, instructors 
can alleviate instructional burden by getting the students involved in teaching the summer course. Students can provide feedback on their peers’ work and assist those learners who need extra help during the classroom tutorial sessions.

Summer class is a great place to start working on improving one’s own teaching, trying out new teaching strategies, and experimenting with novel assignments. Neither the instructor nor the students can withstand the tedium of two- or three-hour lecture presentations and instructor’s monologues. Teaching a summer class compels educators to become more comfortable with impromptu discussions and small group work. It urges instructors to think about and implement more creative teaching methods and learning strategies and take advantage of the modern technologies for the summer course.

It is not a secret that, at present, the reward structure of American colleges and universities and criteria for promotion, tenure, and salary raises privilege the quality and quantity of research over the quality and quantity of teaching. Logically, many representatives of our profession relegate the goal of becoming a better teacher to the side to avail themselves to their research responsibilities. Teaching, however, is not a nemesis of research-related tasks, and the last piece of advice is about finding research opportunities in teaching. A teacher's performance in the class can be used for enhancing her research quality and research productivity (Felder 2010; Prince et al. 2007). One way to accomplish this dual task is to become a scholarly teacher. Summer classes are ideal for formalizing a process for developing and testing an inquiry in the classroom. Teaching and learning can be explored and analyzed using the same logic of inquiry and a methodological tool-kit that educators employ for their disciplinary research. By sharing the results of these in-class discoveries with other educators through various outlets that publish scholarship of teaching, instructors can also expand their lists of contributions to the scholarship 
of discovery and research. Another way for integrating teaching with research is through testing some of the instructor's scholarly ideas and hypotheses in the discussions with students and student focus groups as well as by using students as participants in pilot studies. This kind of engagement of students in one's research is worth doing not only during the summer session, but also in the regular terms. 


\section{References}

Anastasi, J.S. 2007. "Full-Semester and Abbreviated Summer Courses: An Evaluation of Student Performance.” Teaching of Psychology, 31(1): 19-22.

Bonwell, C. and J. Eison. 1991. Active Learning: Creating Excitement in the Classroom. AEHEERIC Higher Education Report No.1. Washington, DC: Jossey-Bass.

Chen, A., Darst, P. W., and R.P. Pangrazi. 2001. “An Examination of Situational Interest and Its Sources.” British Journal of Educational Psychology, 71(3): 383-400.

Crower, A.R, Hyun, E. and M. Kretovics. 2005. "Reflections on Summer Teaching: Academic Rigor or Curriculum Light?” Summer Academe, 5 (January): 7-20.

Dyson, B. 2002. “The Implementation of Cooperative Learning in an Elementary School Physical Education Program.” Journal of Teaching in Physical Education, 22 (February): 69-85.

Felder, R.M. 2010. “The Link between Research and Teaching. Does It Exist?” Chemical Engineering Education, 44 (2): 109-110.

Cooper, H, Charlton, K., Valentine J.C., Muhlenbruck, L., and G.D. Borman. 2000. “Making the Most of Summer School: A Meta-Analytic and Narrative Review.” Monographs of the Society for Research in Child Development, 65(1): 1-127.

Hidi, S. and J.M. Harackiewicz. 2000. "Motivating the Academically Unmotivated: A Critical Issue for the $21^{\text {st }}$ Century.” Review of Educational Research, 70(2): 151-179.

Isaac, J., Sansone, C., and J.L. Smith, J. L. 1999. “Other People as a Source of Interest in an Activity.” Journal of Experimental Social Psychology, 35(3): 239-265.

Kretovics, M.A., Crowe, A.R. and E. Hyun. 2005. “A Study of Faculty Perceptions of Summer Compressed Course Teaching.” Innovative Higher Education, 30(1): 37-51. 
Lewin, Kurt. 1951. Field Theory in Social Science: Selected Theoretical Papers. New York: Harper Bros.

Meyers, C. and T.B. Jones. 1993. Promoting Active Learning. Strategies for the College Classroom. San Francisco, CA: Jossey-Bass Publishers.

Mohamed, Abdi-Rizak. 2008. "Effects of Active Learning Variants on Student Performance and Learning Perceptions.” International Journal for the Scholarship of Teaching and Learning, 2(2). http://academics.georgiasouthern.edu/ijsotl/v2n2/ articles/PDFs/Article_Mohamed.pdf (January 11, 2011).

Prince, M.J., Felder R.M., and R. Brent. 2007. “Does Faculty Research Improve Undergraduate Teaching? An Analysis of Existing and Potential Synergies.” Journal of Engineering Education, 96(4): 283-294.

Scott, P.A. 1996. “Attributes of High-Quality Intensive Course Learning Experiences: Student Voices and Experiences.” College Student Journal 30: 69-77.

Subramaniam, P.R. 2009. “Motivational Effects of Interest on Student Engagement and Learning in Physical Education: A Review.” International Journal of Physics Education, 46(2): 11-19. Williamson, J. and A.S. Gregory. 2010. "Problem-Based Learning in Introductory American Politics Classes.” Journal of Political Science Education, 6(3): 274-296. 
Table 1. Student Population in Introduction to International Politics during Regular and Summer Terms*

\begin{tabular}{|l|c|c|c|}
\hline & Fall 2009 & Fall 2010 & Summer 2010 \\
\hline Total Student Enrollment in the Course & 159 & 180 & 24 \\
\hline Freshmen (\%) & 42 & 31 & 6 \\
\hline Sophomore (\%) & 34 & 39 & 10 \\
\hline Junior (\%) & 17 & 20 & 46 \\
\hline Senior (\%) & 7 & 10 & 38 \\
\hline Liberal Arts (\%) & 91.2 & 87.3 & 70.8 \\
\hline Journalism (\%) & 0.6 & 7.2 & - \\
\hline Engineers (\%) & 3.8 & 2.2 & 16.7 \\
\hline Business (\%) & - & 1.1 & 4.2 \\
\hline Arts and Sciences (\%) & 2.5 & 0.6 & - \\
\hline Others (\%) & & & \\
\hline
\end{tabular}

* This data is taken from Intro to International Politics courses taught by me during the regular terms in 2009 and 2010 and during the summer 2010. 
Table 2. Student Performance in Introduction to International Politics during the Regular and Summer Terms

\begin{tabular}{|l|c|c|c|}
\hline & Fall 2009 & Fall 2010 & Summer 2010 \\
\hline Final Grade A (\%) & 40.3 & 24.2 & 56.5 \\
\hline Final Grade B (\%) & 41.6 & 45.5 & 26.1 \\
\hline Final Grade C (\%) & 10.7 & 18.8 & 8.7 \\
\hline Final Grade D (\%) & 4.7 & 4.8 & 4.3 \\
\hline Final Grade F (\%) & 2.7 & 6.7 & 4.3 \\
\hline Minimum Percentage Point & 31 & 38.4 & 27.4 \\
\hline Maximum Percentage Point & 100 & 96.65 & 98.9 \\
\hline Mean & 85.79 & 81 & 86.9 \\
\hline $\begin{array}{l}\text { Midterm Exam Score (Multiple Choice) } \\
\text { Min/Max/Mean (10\% maximum score) }\end{array}$ & 3.6 / 10 / 7.9 & $4 / 10$ / 8.2 & 6 / 10 / 8.8 \\
\hline $\begin{array}{l}\text { Final Exam Score (Multiple Choice) } \\
\text { Min/Max/Mean (10\% maximum score) }\end{array}$ & $3.2 / 10 / 8.1$ & $2.4 / 9.6 / 7.5$ & 6.4 / 9.6 / 8.3 \\
\hline
\end{tabular}

${ }^{1}$ The challenges of teaching and taking summer courses discussed in this overview were collected from the author's conversations with educators, secondary literature, and readings of the instructors' blogs.

${ }^{2}$ The literature on summer teaching largely consists of surveys of students' and instructors' perceptions of summer school as well as comparisons of student performance in regular and compressed summer courses (Anastasi 2007; Kretovics et al. 2005; Scott 2006). 